\title{
Hypoglycaemic Effects of Decoction of Camelia Sinensis (Lipton Tea) and Citrus Aurantifolia (Lime) On Plasma Glucose Concentration and Weight of Normal Albino Rats
}

\author{
Kasia Benedicta $E^{1 *}$, Ebieri James ${ }^{2}$ and Prohp the Prophet ${ }^{2}$ \\ ${ }^{1}$ Department of Chemical Pathology, Faculty of Basic Medical Sciences, College of Health Sciences, Niger Delta University, Bayelsa \\ State, Nigeria \\ ${ }^{2}$ Department of Biochemistry, Faculty of Basic Medical Sciences, College of Health Sciences, Niger Delta University, Bayelsa State, \\ Nigeria
}

DOI: $10.36348 /$ sijb.2021.v04i03.001

| Received: 13.02.2021 | Accepted: 26.03.2021 | Published: 13.04.2021

*Corresponding author: Dr. Kasia Benedicta E

\section{Abstract}

Camellia sinensis (Lipton tea) contains polyphenols responsible for antioxidant, antidiabetic and anticancer effects. Citrus aurauntifolia is one of the major fruit trees that grows throughout the world and is known for its refreshing juice and health benefits. Some attributes of Citrus aurauntifolia (Lime) include pharmacological properties such as antitumor, anti-inflammatory, and anti-obesity activities. Lime contains phytochemicals such as flavonoids, pectins, vitamin $\mathrm{C}$ and vitamin E. The study was aimed at determining the effects of the decoction of lime and lipton tea on plasma glucose concentration and weight of normal albino rats. Twenty four (24) female albino normal rats of average body weight of $150 \mathrm{~g}$ were randomly placed into two (2) groups of twelve rats each. The plasma glucose concentration was determined by spectrophotometry. The result showed that the plasma glucose decreased significantly $(p<0.05)$ in test group compared to the controls. The rats in the test group experienced some weight loss compared to the control group with no statistical significance $(\mathrm{p}<0.05)$. The histological report showed that the decoction of lime and lipton tea, affected the liver, kidney adversely but had no effect on the heart after two weeks of administration. The decoction of lime and lipton tea in moderate dosage can be clinically significant in the reduction of high plasma glucose levels, hence may be beneficial in the management of diabetes mellitus.

Keywords: Hypoglycaemic, Sinensis, Aurantifolia, Plasma Glucose.

Copyright () 2021 The Author(s): This is an open-access article distributed under the terms of the Creative Commons Attribution 4.0 International License (CC BY-NC 4.0) which permits unrestricted use, distribution, and reproduction in any medium for non-commercial use provided the original author and source are credited.

\section{INTRODUCTION}

Herbal medicine and various types of plantbased therapeutic/prophylactic products have been available for centuries and applied in the treatments of diseases throughout history. It is estimated that about $25 \%$ of orthodox drugs prescribed are derived from plants. For instance certain biological active constituents in plants are useful in the treatment of a number of diseases like malaria fever, heart disease, hypertension, diabetes mellitus, arthritis, asthma and a variety of other health conditions [1].

Tea represents, after water, the most widely consumed beverage in the world [2]. Camellia sinensis (tea) belongs to the family Theaceae, with about 450 species and more than 50 genera. It originated from China but now cultivated both in temperate and tropical countries including Nigeria. The tea is then classed according to its method of processing into different types (as white tea, green tea, black tea, or oolong tea). Tea is an aromatic beverage prepared from its leaves by infusion with boiling water, Numerous research studies [3-7] show promising effects on tea's antioxidant, antibacterial, protection against cancers and cell line growth, blood glucose lowering, weight loss, and many more. It is reported that the presence of some secondary metabolites in tea are responsible for its actions. The major polyphenols in green tea are flavonoids. The four major flavonoids in green tea are the catechinsepicatechin (EC), epigallocatechin (EGC), epicatechingallate (ECG) and epigallocatechin gallate (EGCG). Epigallocatechin gallate is viewed as the most significant active component and possess wide range of health promoting effects [8].

Citrus aurantifolia (Lime) belongs to the group of citrus fruits. The plant belongs to the Family: 
Rutaceae; Genus: Citrus and Species: Citrus aurantifolia .It finds an important place in our daily meals as a valuable adjunct, food and drink flavors and preservatives. It enhances good health and is regarded as a highly valued fruit. Previous studies have confirmed various ethnomedical uses which include antioxidants, anticancer, anticholesterol, antidiabetic, anti-inflammatory, and other effects like treatment of cough, cold, diarrhea etc respectively [9-13]. These functions are largely due to its phytochemical components which include flavonoids, limonoids, coumarins and phytosterols.

Diabetes mellitus is a chronic hyperglycemic condition which is growing at an alarming rate and the number of individuals suffering from the disease throughout the world is predicted to reach 366 million by the year 2030 [14]. There is considerable evidence that reactive oxygen species (ROS) generated due to hyperglycemia lead to many secondary complications of diabetes and oxidative damage $[15,16]$. Therefore a promising approach for hyperglycemic conditions and complications might be a combination therapy utilizing dietary polyphenols and hypoglycemic drugs at a suboptimal dosage to minimize any potential adverse effects.

This study is based on the hypothesis that the phytochemical compounds found in green tea (Camellia sinensis) and lime (Citrus aurantofolia) have antidiabetic and weight reducing properties. The purpose of this study therefore, aims to investigate hypoglycemic effects of the decoction of lipton tea and lime extracts.

\section{MATERIALS AND METHODS MATERIALS \\ Chemicals/Reagents}

All chemical/reagents used were of analytical grade and are as manufactured by Randox laboratory Ltd in England. The kit was supplied by Pyrex reagent, a commercial supplier.

\section{Experimental Animals}

About twenty four (24) healthy female albino rats of Wistar strain aged 3 weeks and with an average weight of $150 \mathrm{~g}$ were used in this study. They were obtained from the animal house of Vetcare pharmaceuticals, Port-Harcourt and maintained under standard laboratory conditions. The animals were acclimatized for one week and during this period were fed with pelleted grower's marsh and clean distilled water.

\section{Feeds}

Rats were fed with pelleted grower's marsh throughout the duration of the experiment

\section{The Lime and Lipton tea}

Fresh Lime specimen and Lipton tea were purchased from Amassoma market, Bayelsa state.

\section{METHODS \\ Preparation of Extracts}

Two fresh (2) limes were thoroughly washed with clean water and cut into 2 apiece. They were then introduced into a $500 \mathrm{ml}$ beaker containing $200 \mathrm{ml}$ of pure water (distilled water) and a bag of lipton tea. The mixture was allowed to boil for 20minutes and then to cool down under room temperature and sieved with the aid of a sterile cheese cloth. The extract was stored in a clean bottle and kept in the refrigerator at $4^{\circ} \mathrm{C}$ overnight and subsequently administered to the rats. This procedure was repeatedly done to have a routine fresh sample.

\section{Administration of Extract}

The decoction of lime and lipton tea (experimental sample) was administered to the experimental animals orally (P.O) using a garage at $2 \mathrm{ml} / \mathrm{Kg}$ body weight of rat three times daily ( 8 hourly).

\section{ETHICAL CLEARANCE}

The entire experimental protocol was performed in accordance with the Institutional Animal Ethical Committee (IAEC), in line with the directions of the Committee for the Purpose of Control and Supervision of Experiments on Animals (CPCSEA) in Niger Delta University, Wilberforce Island, Bayelsa State, Nigeria.

\section{Blood Collection}

Experimental rats were sacrificed periodically for blood collection. Blood collected was immediately subjected to centrifugation at 3000rotation for 20minutes to obtain the plasma. Analysis was carried out immediately after centrifugation.

\section{Experimental Design}

The 24 healthy female albino rats of Wistar strain after one week acclimatization were randomly distributed into two groups containing 12 rats each.

Group 1 served as control and received pelleted growers marsh and distilled water throughout the experiment.

Group 2 served as the test and was administered experimental sample at $2 \mathrm{ml} / \mathrm{Kg}$ body weight and also fed with pelleted grower's marsh and clean distilled water throughout the experiment.

\section{Glucose Assay}

Glucose was determined by enzymatic oxidation in the presence of glucose oxidase as described by Randox Laboratories Limited, England. The hydrogen peroxide formed reacts under the catalysis of the peroxidase with the phenol and 4- 
aminophenazone to form a red-violet quinoimine dye as indicator. Exactly $10 \mu \mathrm{l}$ of the plasma of the blood collected in a fluoride oxalate bottle was transferred into the test tubes containing $1000 \mu \mathrm{l}$ of the reagent. Samples were thoroughly mixed and incubated at $37^{\circ} \mathrm{C}$ for 10 minutes. The absorbance values were read at 540nm using the glucose blank as the blank.

Glucose concentration $(\mathrm{mg} / \mathrm{dl})=$ A sample/A standard $\mathrm{X}$ Standard conc. ( $\mathrm{mg} / \mathrm{dl})$.

\section{Histological Assessment of Tissue}

The rats were sacrificed periodically and dissected to obtain the heart, liver and kidney for histological studies. The tissue samples were immediately preserved by immersion into $10 \%$ formalin. The fixed tissue sample were cleared in xylene and embedded in paraffin wax and sections were cut using 5-micron in a rotator microtome. The sections were then examined using the light microscopy after staining with hematoxylin and eosin dye and interpreted by a specialist.

\section{STATISTICAL ANALYSIS}

Data was expressed as mean \pm standard deviation. The significant difference between the test and control were analysed using unpaired t-test. Data were analysed using the SPSS software (SPSS Inc. Chicago, USA). $\mathrm{P} \leq 0.05$ was set at the level of significance.

\section{RESULTS}

A total of 24 healthy female albino rats were studied divided into 12 experimental (test) and 12 control female rats. Table 1 show the mean plasma glucose concentrations in normal female albino rats following oral administration of the decoction of lime (Citrus aurauntifolia) and liption tea (Camellia sinensis) for 14 days. There was a significant reduction in the plasma glucose concentration of the experimental (test) group rats especially on days 7 and 14 when compared with the controls $(\mathrm{p} \leq 0.05)$.

Table-1: Mean plasma concentration $(\mathrm{mg} / \mathrm{dl})$ of glucose in normal rats after 14 days of administration of the decoction of lime and Lipton tea decoction.

\begin{tabular}{|l|l|l|l|l|}
\hline GROUPS/DAYS & DAY 0 & DAY 1 & DAY 7 & DAY 14 \\
\hline TEST & $57.91 \pm 0.20^{\mathrm{a}}$ & $55.02 \pm 1.22^{\mathrm{a}}$ & $44.34 \pm 0.46^{\mathrm{a}}$ & $35.26 \pm 0.80^{\mathrm{a}}$ \\
\hline CONTROL & $58.60 \pm 0.09^{\mathrm{a}}$ & $58.50 \pm 0.80^{\mathrm{a}}$ & $58.23 \pm 1.22^{\mathrm{b}}$ & $57.43 \pm 1.22^{\mathrm{b}}$ \\
\hline
\end{tabular}

Values are represented as mean \pm STD of triplicate determinations. Values with the different superscript alphabets are significant statistically $(\mathrm{P}<0.05)$.

Table 2 shows the mean weight of rats control $(\mathrm{P}<0.05)$. The rats in the test group experienced reduction in the body weight when compared with the control values however, the differences were not statistically significant $(\mathrm{P}<0.05)$.

Table-2: Mean weight (g) of rats administered decoction of lime (citrus aurauntifolia) and lipton (camellia sinensis)

\begin{tabular}{|l|l|l|l|l|}
\hline Group/Days & Day 0 & Day 1 & Day 7 & Day 14 \\
\hline Test & $146.07 \pm 3.24^{\mathrm{b}}$ & $149.52 \pm 12.53^{\mathrm{a}}$ & $139.4 \pm 16.95^{\mathrm{a}}$ & $155.93 \pm 18.22^{\mathrm{a}}$ \\
\hline Control & $133.53 \pm 4.67^{\mathrm{a}}$ & $138.78 \pm 14.19^{\mathrm{a}}$ & $161.07 \pm 5.78^{\mathrm{a}}$ & $169.43 \pm 3.77^{\mathrm{a}}$ \\
\hline
\end{tabular}

Values are presented as mean \pm SD of triplicate determinations. Values with different superscript alphabets are statistically significant $(\mathrm{P}<0.05)$.

\section{Histopathology of liver, kidney and heart}
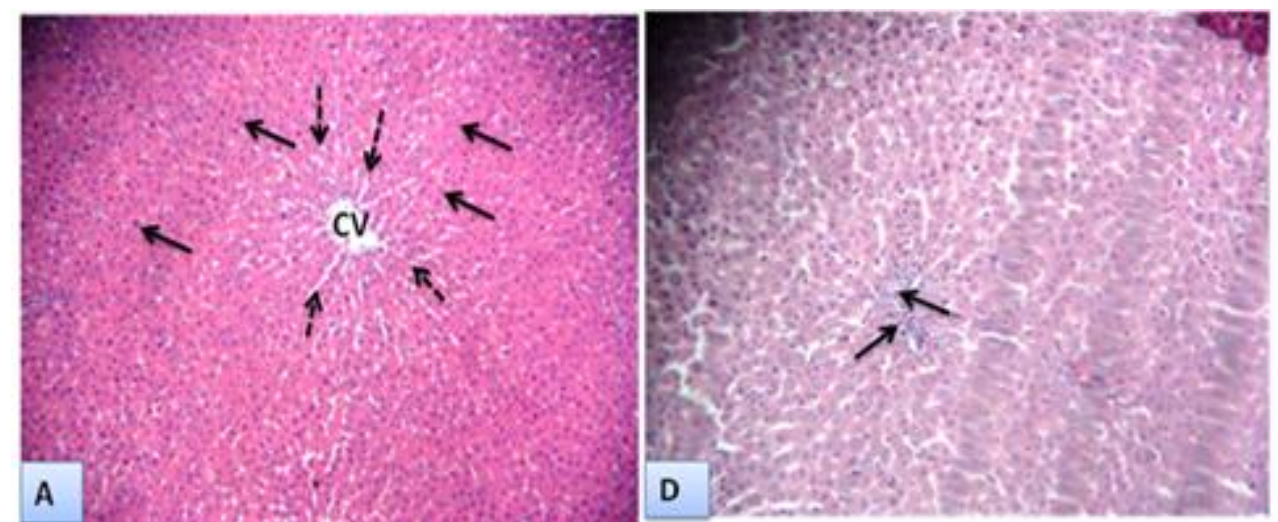

Fig-3: (Photomicrograph of Liver): Group A (Control) shows normal Central vein= CV, with well radiating Hepatocytes (Arrow) and sinusoids (Dash arrow). Group D has normal hepatocytes and stroma but are mildly infiltrated around the portal triad (Arrow) 

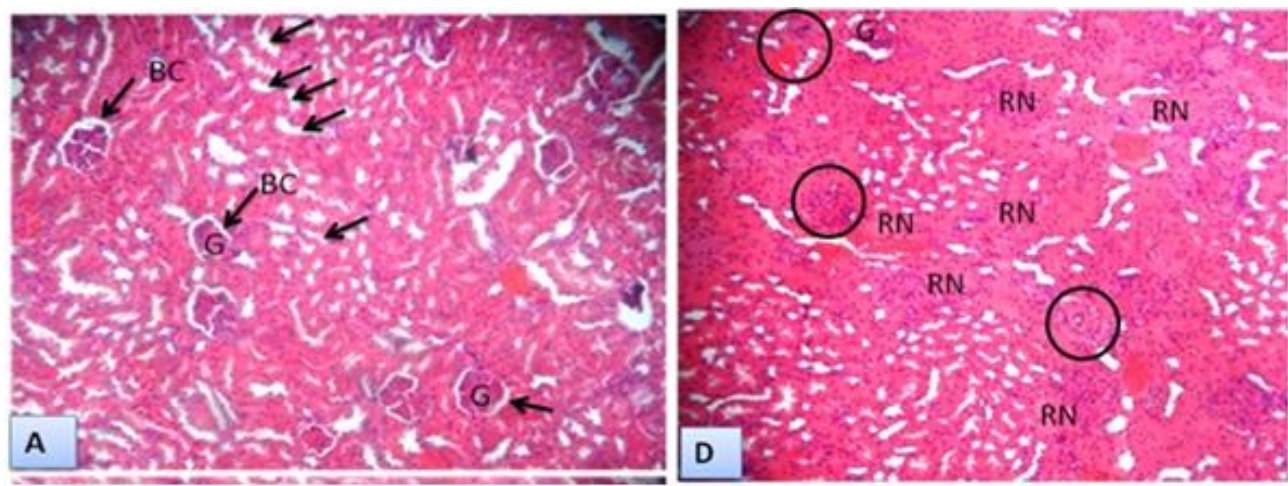

Fig-4: Photomicrograph of Kidney: Group A (Normal control) with normal Glomeruli (G), Bowman's capsule (BC) and Renal Tubule (RT). Group D is characterized by dissolution of the glomeruli (Circle) and Renal necrosis (RN). H\&E x100
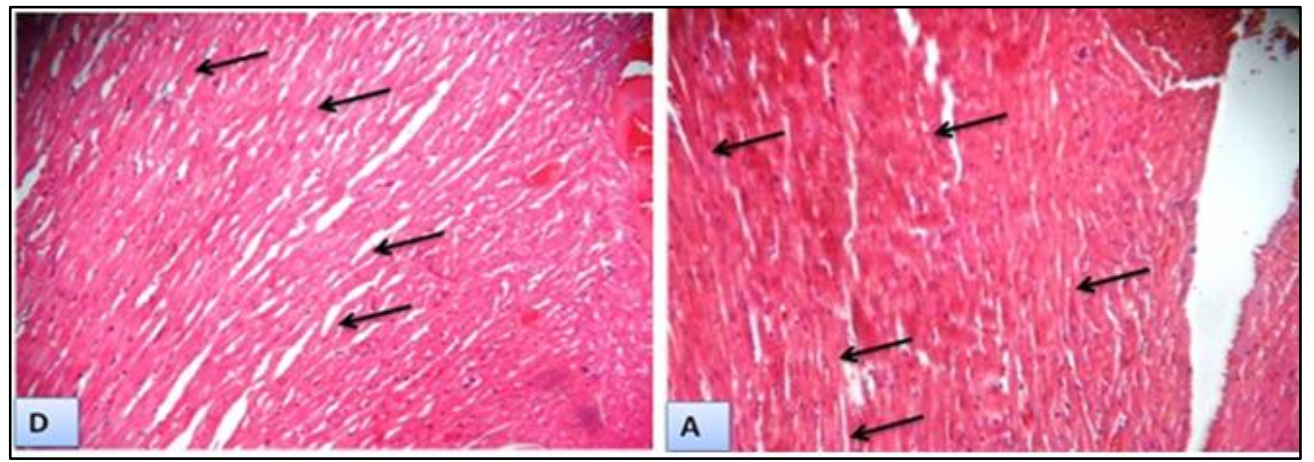

Fig-5: Photomicrograph of the Heart: Group A (control) with parallel pattern of myofibrils with centrally located nuclei (Arrow), alongside their branches. Groups D is similar to the control (Group A). H\&E x100

\section{DISCUSSION}

Tea is one of the most widely consumed beverages in the world made from the leaves of Camellia sinensis. Green tea is the non-oxidized /non fermented product contains high quantities of several polyphenolic flavonoid compounds such as epicatechin, epicatechingallate, epigallocatechin, and epigallocatechingallate (EGCG) which were reported to have antioxidant properties well thought-out to maintain and improve health.8 our findings clearly showed that the oral administration of tea extract significantly reduced glucose levels in the test rats. The results are in agreement with previous human and animal studies [17-19]. Another study by Ramadan et al. [20] reported that green tea aqueous extract significantly alleviated hyperglycemia (resulting from type 1 and 2 diabetes) induced by alloxan or cholesterol-rich diets in rats. Very little is known about the mechanism of action of hypoglycemic effect of green tea but the probable proposed reasons for this were based on high quantities of active compoundscatechins which increase insulin-stimulated glucose uptake, inhibition of the intestinal glucose transport system and decrease in expression of genes that control gluconeogenesis [2].

This is however contrary to study by $\mathrm{Wu}$ et al., [22] who reported that the supplementation of green tea catechins does not change the blood glucose concentration in normal rats.
In this study, the test group experienced a nonstatistical significant reduction in weight compared to the controls. This is keeping with previous studies [7, $23,24]$. The possible explanation is that the contents (catechins and caffeine in tea) might act to exert thermogenic and anti-obesity action.

This study reported the hypoglycemic effect of Citrus aurantifolia in albino rats which is in keeping with report by Ibrahim FA et al. [25] on the antidiabetic effects of the leaf essential oils. This is also similar to Ramya et al., [26] Akbar et al. [27] and Herin et al. [28] who reported on the combined effects of extracts of Citrus aurantifolia and Punica granatum, garlic and Cinnamomum burmannii respectively. In all these, they reported their additive effects in the reduction of blood glucose levels with no effect on weight. It was however, important to note that non- significant weight reduction was observed in this study as reported earlier [7, 23, 24]. This is probably due to the additive effect of the tea (Camellia sinensis) which has anti-obesity action to lime (Citrus aurantifolia).

Histopathological studies of the liver, kidney and heart revealed that the decoction of lime and lipton tea caused dissolution of the glomeruli and renal necrosis while having mild effect on the liver and no effect on the heart tissue after two weeks of continuous administration. This is in conformity with previous studies which reported nephrotoxic effects from these extracts [29]. The probable explanation of this may be 
due to altered metabolism and toxicity from continuous use as with most diets due to prolonged exposure to phytochemical constituents. It can be concluded from this study that extracts combination of lipton tea and lime in moderate doses may be promising as alternative preventive medicine for management of diabetes mellitus and its complications.

\section{CONCLUSION}

The results obtained suggests that the presence of polyphenols such as flavonoids in lime and lipton tea, may be responsible for the reduction in plasma glucose concentration, Histopathology results showed inflamed kidney from continuous dosage probably from altered metabolism and toxicity. From this result the decoction of lime and lipton in moderate doses may be promising as alternative preventive medicine for management of diabetes mellitus and its complications. However, despite these evidences of promising effects in rodents, human studies are deficient and inconsistent. Therefore, further studies on the screening and isolation of the phytochemicals (secondary plant metabolites) in these plants extracts along with their mode of action are required as this will enhance their effective use as plantbased drugs such as anti-hyperglycemic agents in humans with diabetes mellitus.

\section{REFERENCES}

1. Ukwubile, C. A., Malgwi, T. S., Dibal, M. Y., \& Bababe, A. B. Phytochemical Composition and Toxicity Evaluation of Camellia Sinensis (L.) O. Kuntze (Theaceae)(Green Tea) Leaves Collected from Mambila Beverages Ltd Nigeria.

2. Stangl, V., Dreger, H., Stangl, K., \& Lorenz, M. (2007). Molecular targets of tea polyphenols in the cardiovascular research, 73(2), 348-358.

3. Chan, E. W. C., Lim, Y. Y., \& Chew, Y. L. (2007). Antioxidant activity of Camellia sinensis leaves and tea from a lowland plantation in Malaysia. Food chemistry, 102(4), 1214-1222.

4. Florence, A.R., Joselin, J., Shyninbrintha, T.S., Sukumaran, S., Jeeva, S. (2010). Preliminary phytochemical studies of selected members of the family Theaceae for bioactive constituents. Bio Sci Disc, 5(1), 85-96

5. Wang, Z. G., \& Ren, J. (2002). Current status and future direction of Chinese herbal medicine. Trends in Pharmacological Sciences, 23(8), 347-348.

6. Anorue, E. C., Mbegbu, E. C., Ngwu, G. I., Ibemenuga, K. N., \& Eyo, J. E. (2019). Hypoglycaemic and Hypolipidemic Effects of Black Brand of Lipton Tea (Camellia sinensis) on Normal Male Albino Rats. Notulae Scientia Biologicae, 11(1), 94-101.

7. Chantre, P., \& Lairon, D. (2002). Recent findings of green tea extract AR25 (Exolise) and its activity for the treatment of obesity. Phytomedicine, 9(1), 3-8.
8. Patil, L., \& Balaraman, R. (2011). Effect of green tea extract on doxorubicin induced cardiovascular abnormalities: antioxidant action. Iranian journal of pharmaceutical research: IJPR, 10(1), 89.

9. Pallavi, M., Ck, R., Krishna, V., \& Parveen, S. (2017). Quantitative phytochemical analysis and antioxidant activities of some Citrus fruits of South India. Asian Journal of Pharmaceutical and Clinical Research, 10(12), 198-205.

10. Esparza-Martínez, J. F., Solis, P. G., MirandaLópez, R., \& Peña-Caballero, V. (2019). Inhibition of proliferation of colorectal Cancer cells by phenolic extracts of mandarin (Citrus reticulate) and lime (Citrus aurantifolia) fruit waste. J. Food Nutr. Res, 7, 560-567.

11. Lin, L. Y., Chuang, C. H., Chen, H. C., \& Yang, K. M. (2019). Lime (Citrus aurantifolia (Christm.) Swingle) essential oils: volatile compounds, antioxidant capacity, and hypolipidemic effect. Foods, 8(9), 398.

12. Şeker Karatoprak, G., Yücel Aşık, Ç., Çakır, A., \& Köngül Şafak, E. (2020). In vitro pharmacological screening of antioxidant, cytotoxic and enzyme inhibitory activities of Citrus aurantifolia Linn. Dried fruit extract. International journal of environmental health research, 1-10.

13. Amorim, J. L., Simas, D. L. R., Pinheiro, M. M. G., Moreno, D. S. A., Alviano, C. S., da Silva, A. J. R., \& Dias Fernandes, P. (2016). Anti-inflammatory properties and chemical characterization of the essential oils of four citrus species. PloS one, 11(4), e0153643.

14. Islam, M. S., \& Choi, H. (2007). Green tea, antidiabetic or diabetogenic: A dose response study. Biofactors, 29(1), 45-53.

15. Haidari, F., Keshavarz, S. A., Shahi, M. M., Mahboob, S. A., \& Rashidi, M. R. (2011). Effects of parsley (Petroselinum crispum) and its Flavonol constituents, Kaempferol and Quercetin, on serum uric acid levels, biomarkers of oxidative stress and liver xanthine Oxidoreductase Aactivity inOxonate-induced Hyperuricemic rats. Iranian journal of pharmaceutical research: IJPR, 10(4), 811.

16. Baynes, J. W., \& Thorpe, S. R. (1999). Role of oxidative stress in diabetic complications: a new perspective on an old paradigm. Diabetes, 48(1), 19.

17. Panagiotakos, D. B., Lionis, C., Zeimbekis, A., Gelastopoulou, K., Papairakleous, N., Das, U. N., \& Polychronopoulos, E. (2009). Long-term tea intake is associated with reduced prevalence of (type 2) diabetes mellitus among elderly people from Mediterranean islands: MEDIS epidemiological study. Yonsei medical journal, 50(1), 31 .

18. Igarashi, K., Honma, K., Yoshinari, O., Nanjo, F., \& Hara, Y. (2007). Effects of dietary catechins on glucose tolerance, blood pressure and oxidative 
status in Goto-Kakizaki rats. Journal of nutritional science and vitaminology, 53(6), 496-500.

19. Wolfram, S., Raederstorff, D., Preller, M., Wang, Y., Teixeira, S. R., Riegger, C., \& Weber, P. (2006). Epigallocatechin gallate supplementation alleviates diabetes in rodents. The Journal of nutrition, 136(10), 2512-2518.

20. Ramadan, G., Nadia, M., \& Abd El-Ghffar, E. A. (2009). Modulatory effects of black v. green tea aqueous extract on hyperglycaemia, hyperlipidaemia and liver dysfunction in diabetic and obese rat models. British Journal of Nutrition, 102(11), 1611-1619.

21. Babu, P. V. A., Sabitha, K. E., \& Shyamaladevi, C. S. (2006). Therapeutic effect of green tea extract on oxidative stress in aorta and heart of streptozotocin diabetic Interactions, 162(2), 114-120.

22. Wu, L. Y., Juan, C. C., Ho, L. T., Hsu, Y. P., \& Hwang, L. S. (2004). Effect of green tea supplementation on insulin sensitivity in SpragueDawley rats. Journal of agricultural and food chemistry, 52(3), 643-648.

23. Boschmann, M., \& Thielecke, F. (2007). The effects of epigallocatechin-3-gallate on thermogenesis and fat oxidation in obese men: a pilot study. Journal of the American College of Nutrition, 26(4), 389S-395S.

24. Al-Hilfy, J. H. Y. (2012). Effect of green tea aqueous extract on body weight, glucose level, and kidney functions in diabetic male albino rats. AlNahrain Journal of Science, 15(3), 116-166.

25. Ibrahim, F. A., Usman, L. A., Akolade, J. O., Idowu, O. A., Abdulazeez, A. T., \& Amuzat, A. O. (2019). Antidiabetic potentials of Citrus aurantifolia leaf essential oil. Drug research, 69(04), 201-206.

26. Ramya, S., Narayanan, V., Ponnerulan, B., Saminathan, E., \& Veeranan, U. (2020). Potential of peel extracts of Punica granatum and Citrus aurantifolia on alloxan-induced diabetic rats. BeniSuef University Journal of Basic and Applied Sciences, 9(1), 1-11.

27. Karimi, A., \& Nasab, N. K. (2014). Effect of garlic extract and Citrus aurantifolia (lime) juice and on blood glucose level and activities of aminotransferase enzymes in streptozotocininduced diabetic rats. World J Pharm Sci, 2(8), 821-827.

28. Mawarti, H., Khotimah, M. Z. A. A., \& Rajin, M. (2018). Ameliorative effect of Citrus aurantifolia and Cinnamomum burmannii extracts on diabetic complications in a hyperglycemic rat model. Tropical Journal of Pharmaceutical Research, 17(5), 823-829.

29. Chriscensia, E., Wibowo, E. C., Enriko, G., Wijaya, O. C., \& Sahamastuti, A. A. T. (2020). Phytochemical Screening, Therapeutic Benefits, and Adverse Effects of Citrus aurantifolia-A Review. Indonesian Journal of Life Sciences| ISSN: 2656-0682 (online), 2(2), 56-69. 